Vol 12, Issue 4, 2019

\title{
HYDROALCOHOLIC EXTRACT OF MATRICARIA CHAMOMILLA LINN. AMELIORATES LIPIDS, LIPOPROTEINS, AND PARAOXONASE IN ISOPROTERENOL-INDUCED MYOCARDIAL INFARCTION IN WISTAR RATS
}

\author{
VADIVELAN RAMACHANDRAN*, GAUTAM ADHIKARI \\ Department of Pharmacology, JSS College of Pharmacy, (JSS Academy of Higher Education and Research), Nilgiris, Tamil Nadu, India.
} Email: vadivelanr@jssuni.edu.in

Received: 31 December 2018, Revised and Accepted: 20 February 2019

\begin{abstract}
Objective: The objective of this study was to evaluate the effect of the hydroalcoholic extract of Matricaria Chamomilla Linn. (CHAE) on lipids, lipoproteins, and antioxidants activity in isoproterenol (ISO)-induced myocardial infarcted rats.

Methods: ISO (85 mg/kg, s.c.)-induced myocardial infarction for 2 consecutive days at an interval of $24 \mathrm{~h}$. Rats were pretreated with CHAE (100 and $200 \mathrm{mg} / \mathrm{kg}$, oral) for a period of 20 days and ISO was injected on 21 and 22 days at $24 \mathrm{~h}$ intervals and after $24 \mathrm{~h}$, blood was collected through retroorbital plexus for the estimation of lipids, lipoproteins, and antioxidants assay.

Results: In the present study, ISO caused a significant increase in the concentration of total cholesterol, triglycerides, low-density lipoprotein cholesterol (LDL-C), very LDL-C, and lipid peroxidation whereas a significant decrease in the concentration of high-density lipoprotein-C. ISO administration also significantly decreased the activities of paraoxonase (PON) enzyme. Oral pre-treatment of CHAE at doses of $100 \mathrm{and} 200 \mathrm{mg} / \mathrm{kg}$ body weight (bw) for 20 days challenged with a concurrent injection of ISO (85 mg/kg bw) on 21 and 22 days significantly attenuated these alterations and restored the levels of lipids and lipoproteins. In addition, CHAE significantly elevated the serum antioxidants enzyme PON and catalase (CAT).
\end{abstract}

Conclusion: The report revealed that pre-treatment with CHAE ameliorated lipid and lipoprotein and increased the antioxidant PON and CAT activity and decreased LPO level in ISO-treated male albino Wistar rats.

Keywords: Matricaria chamomilla Linn., Myocardial infraction, Isoproterenol, Paraoxonase, Lipid peroxidation, Catalase.

(C) 2019 The Authors. Published by Innovare Academic Sciences Pvt Ltd. This is an open access article under the CC BY license (http://creativecommons. org/licenses/by/4. 0/) DOI: http://dx.doi.org/10.22159/ajpcr.2019.v12i4.31145

\section{INTRODUCTION}

Myocardial infarction (MI) or heart attack is the leading cause of death for both men and women all over the world. MI occurs when blood supply is insufficient to the myocardium, death of myocardial muscle occurs, a condition known as ischemia. Prolonged ischemia of the myocardium leads to necrosis of myocardium cell, which is referred to as MI [1]. MI is the acute condition that occurs due to imbalance between coronary blood supply and demand [2]. The risk factors of cardiovascular diseases (CVDs) are high levels of total cholesterol (TC), triglycerides (TGs), lowdensity lipoprotein cholesterol (LDL-C), and apolipoproteins A-I and low levels of high-density lipoprotein cholesterol (HDL-C). Cardiovascular diseases are directly or indirectly related to oxidative stress that causes molecular and cellular damage. Numerous medicinal plants have been evaluated for cardiovascular diseases in India and various parts of the world using cardiotoxic models [3].

Isoproterenol (ISO) is a $\beta$-adrenergic agonist that causes severe stress on the myocardium in heart muscle, leading to the necrosis of myocardium [4]. ISO causes an increase in the levels of serum and myocardial lipids and also increases the level of LDL-C in the blood that causes the blockage of arteries favoring CVD [5]. ISO stimulates lipid peroxidation (LPO) by inducing free radical production, which may be a causative factor of irreversible damage to the myocardial membranes [6]. Oxidative stress and oxygen-free radicals together lead to the generation of atherosclerotic lesions by the formation of oxidized LDL from LDL, which is the underlying cause of MI [7].

Matricaria chamomilla Linn. (CHAE) (synonym: Matricaria recutita) commonly known as chamomile or German chamomile belongs to the family Asteraceae [8,9]. Chamomile as a whole plant has been used traditionally in different forms for the treatment of multiple medical complaints such as common cold, bronchitis, gastrointestinal spasms, epilepsy, hypertension, neuralgia, toothache, dysmenorrhea, eczema, impetigo, indigestion, colic, and diarrhea [10-12]. Its flowers are also used as carminative and antipyretic, while its oil has been used in rheumatism, flatulence, and colic $[13,14]$.

Phytochemical studies revealed the presence of alpha-bisabolol, cis-spiroethers sesquiterpenes (anthecotulid), cadinene, farnesene, furfural, spathulenol, and proazulene (Matricaria and matricin) as plant constituents. The presence of tannin in chamomile has also been detected $<1 \%[15,16]$.

Pharmacological investigations showed that Matricaria chamomilla possesses anti-inflammatory [17], antispasmodic [18], antibacterial [19], digestive [20], antioxidant, and antidiabetic [21,22] activities.

Paraoxonase (PON) is synthesized in the liver and is bound to plasma HDL-C [23]. PON has treated as a component of the plasma antioxidant system. This enzyme prevents the oxidation of LDL-C and acts as a protective enzyme against atherogenesis. PON protects against atherosclerosis by reducing HDL-C peroxidation and protect plasma membranes from free radical injury [24]. Human serum PON has been shown to hydrolyze oxidized lipids and thus to decrease oxidative stress on serum lipoproteins [25]. Low activity of serum PON has been reported in diseases associated with hypercholesterolemia, atherosclerosis and increased prevalence of CVD [26].

In the present study, we assessed the ameliorative effect of CHAE on lipids, lipoproteins, catalase (CAT) activity, LPO, and PON in ISOadministered myocardial infarcted rats. 


\section{MATERIALS AND METHODS}

\section{Collection and authentication of plant material}

Matricaria chamomilla collected from local areas of Coimbatore district, Tamil Nadu, India. The collected flower parts of Matricaria chamomilla were authenticated by Dr. S Rajan, Field Botanist, Survey of Medicinal Plants and Collection Unit, Central Council for Research in Homoeopathy, Department of AYUSH, the Nilgiris, Tamil Nadu.

\section{Extraction procedure}

The dried plant material weighing $500 \mathrm{~g}$ used for extraction and soaked in $70 \%$ ethanol for 3 days, with occasional shaking. The soaked material was filtered through a muslin cloth and then through a Whatman qualitative Grade 1 filter paper. This procedure repeated 3 times and the combined filtrate was evaporated using a rotary evaporator to get the final aqueous-ethanolic extract of Matricaria chamomilla, yielding $25 \% \mathrm{w} / \mathrm{w}[27]$.

\section{Experimental animals}

Healthy, adult Male Wistar albino rats (180-250 g) obtained from the central animal house facility, JSS College of Pharmacy, Udhagamandalam, Tamil Nadu. The animals were exposed in a well-ventilated room and were exposed to $12 \mathrm{~h}$ day and night cycle with a temperature between $22 \pm 3^{\circ} \mathrm{C}$. The animals were housed in large spacious, hygienic polypropylene cages during the course of the experimental period and fed with water ad libitum. All the experiments were performed after prior approval from the Institutional Animal Ethics Committee (JSSCP/ IAEC/M.PHARM/PH.CPLOGY/04/2013-14).

\section{Induction of experimental MI}

ISO was dissolved in normal saline and was subcutaneously injected into rats $(85 \mathrm{mg} / \mathrm{kg})$ at $24 \mathrm{~h}$ intervals for 2 days to induce experimental MI [28].

\section{Experimental design}

After a 1-week acclimation period, animals randomly divided into four groups (with six rats in each group) and treated as follows:

Group I - Untreated control rats

Group II - Pre-treatment of rats with ISO $(85 \mathrm{mg} / \mathrm{kg}$ bw)

Group III - Pre-treatment of rats with CHAE $100 \mathrm{mg} / \mathrm{kg}$ (oral) + ISO

(85 mg/kg)

Group IV - Pre-treatment of rats with CHAE $200 \mathrm{mg} / \mathrm{kg}$ (oral) + ISO $(85 \mathrm{mg} / \mathrm{kg})$
CHAE was solubilized in distilled water. CHAE orally pre-treated to the rats for 20 days using an intragastric tube. ISO was solubilized in distilled water and administered to the rats by subcutaneous injection for the past 2 consecutive days. Animals were sacrificed by cervical decapitation. Blood was collected from heart puncture to separate serum and plasma. Tissue samples were separated and refrigerated at 80 LC.

\section{Biochemical measurements}

The levels of serum TC and TGs were estimated using diagnostics kits from Erba Diagnostics (Mumbai) as described by Allian et al. [29]. HDL-C was estimated by utilizing the kit of Siemens Diagnostics Ltd., India, as described by Richmond [30]. Very LDL-C (VLDL-C) was calculated as VLDL-C $=$ TG $/ 5$, whereas LDL-C was calculated as LDL-C = TC - (HDL-C + VL DL-C). Malondialdehyde (MDA) level was measured to estimate LPO by the method of Okhawa et al. [31]. PON activity was assayed by the method of Gan et al. [32].

\section{Statistical analysis}

Results analyzed statistically by performing one-way analysis of variance (ANOVA) followed by Tukey's multiple comparison tests to assess differences between the groups. Data considered statistically significant at $p<0.05$. All the statistics were performed using GraphPad Prism, version 6.

\section{RESULTS AND DISCUSSION}

\section{Effect of CHAE on lipids and lipoproteins}

Fig. 2, and Tables 1 and 2 depict the effect of CHAE on serum lipids and lipoproteins (TC, TG, HDL-C, VLDL-C, and LDL-C) in normal and ISO-administered groups. Rats injected with ISO exhibited a significant $(p<0.05)$ increase in the levels of serum TC, TG, LDL-C, and VLDL-C, except HDL-C which showed a significant $(p<0.05)$ decrease

Table 1: Effect of CHAE on cholesterol and triglycerides levels

\begin{tabular}{lll}
\hline Groups & Cholesterol (mg/dl) & Triglycerides $(\mathrm{mg} / \mathbf{d l})$ \\
\hline Control & $55.80 \pm 1.881$ & $56.92 \pm 2.150$ \\
ISO $85 \mathrm{mg} / \mathrm{kg}$ & $86.17 \pm 1.748$ & $185.2 \pm 2.151$ \\
CHAE $100 \mathrm{mg} / \mathrm{kg}$ & $65.62 \pm 1.957$ & $139.2 \pm 3.195$ \\
CHAE $200 \mathrm{mg} / \mathrm{kg}$ & $63.73 \pm 2.035$ & $79.43 \pm 2.997$ \\
\hline
\end{tabular}

Values represent mean \pm SEM; $n=6$; ${ }^{*} \mathrm{p}<0.05$ versus control. ${ }^{*} \mathrm{p}<0.05$ versus ISO one-way ANOVA followed by Tukey's multiple comparisons test

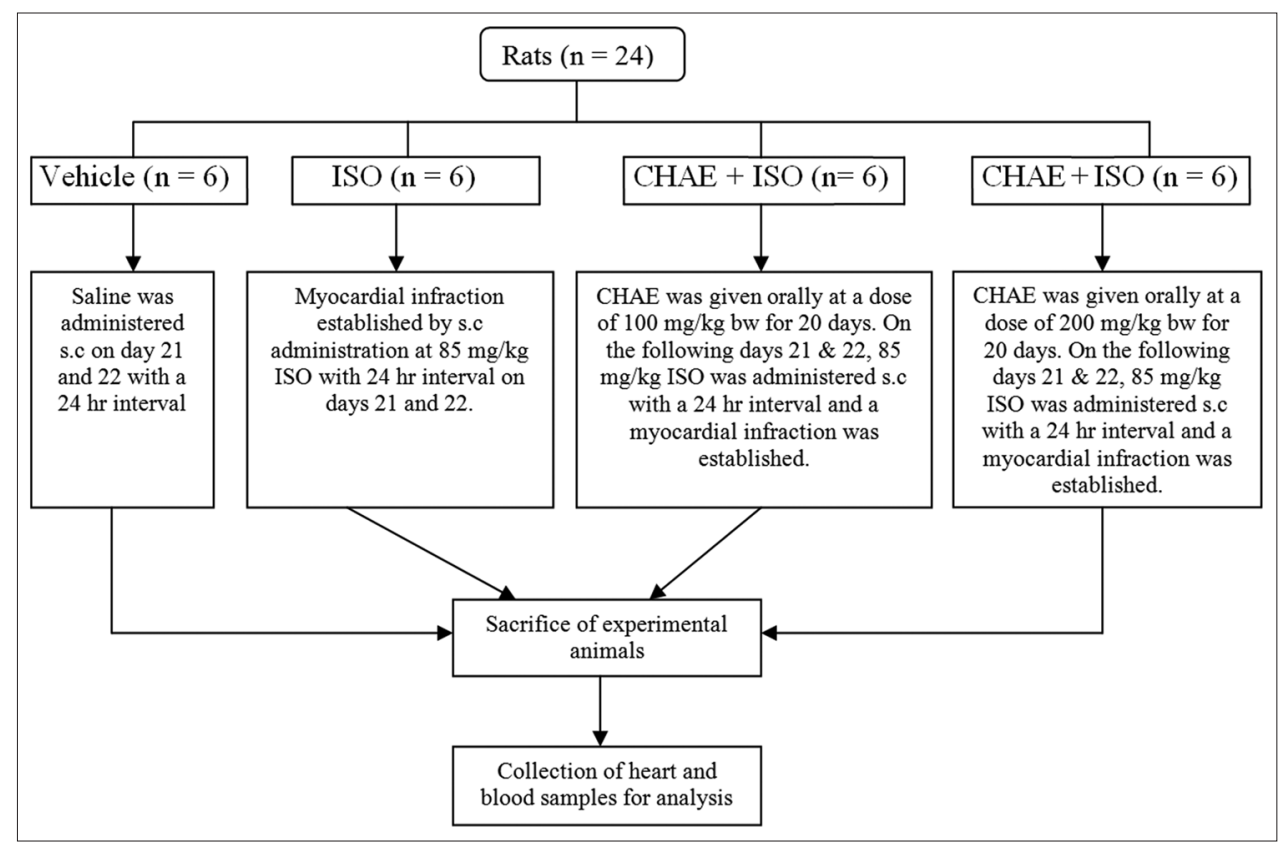

Fig. 1: Schematic representation of the experimental design of the study 
Table 2: Effect of CHAE on LDL-C, VLDL-C, and HDL-C levels

\begin{tabular}{llll}
\hline Groups & LDL-C (mg/dl) & VLDL-C (mg/dl) & HDL-C (mg/dl) \\
\hline Control & $10.17 \pm 0.587$ & $11.386 \pm 0.43$ & $34.24 \pm 2.038$ \\
ISO $85 \mathrm{mg} / \mathrm{kg}$ & $36.16 \pm 0.03$ & $370.05 \pm 0.43$ & $12.96 \pm 1.361$ \\
CHAE $100 \mathrm{mg} / \mathrm{kg}$ & $20.66 \pm 0.21$ & $27.84 \pm 0.64$ & $17.12 \pm 1.525$ \\
CHAE $200 \mathrm{mg} / \mathrm{kg}$ & $20.78 \pm 0.656$ & $15.886 \pm 0.6$ & $27.06 \pm 2.091$ \\
\hline
\end{tabular}

Values represent mean \pm SEM; $\mathrm{n}=6$; ${ }^{*} \mathrm{p}<0.05$ versus control. ${ }^{*} \mathrm{p}<0.05$ versus ISO one-way ANOVA followed by Tukey's multiple comparison tests. LDL-C: Low-density lipoprotein cholesterol, VLDL-C: Very low-density lipoprotein cholesterol, HDL-C: High-density lipoprotein cholesterol

when compared to control rats. Pre-treatment with CHAE (100 and $200 \mathrm{mg} / \mathrm{kg} \mathrm{bw}$ ) dose dependently decreased serum TC, TG, LDL-C, and VLDL-C levels significantly $(\mathrm{p}<0.05)$ and increased serum HDL-C levels significantly $(\mathrm{p}<0.05)$ when compared to ISO administered rats. Treatment of CHAE at $200 \mathrm{mg} / \mathrm{kg}$ bw in ISO-administered rats decreased the serum TC and LDL-C almost to near normal but not significantly $(\mathrm{p}<0.05)$ when compared to the control rats.

Lipids play a significant role in CVD. Hyperlipidemia and hypercholesterolemia are vital risk factors in the progress of MI. ISOadministered MI is allied with elevated levels of circulatory lipids. In this study, ISO-administered rats showed significantly increased levels of TC, TGs in serum. The increased level of cholesterol in ISO-treated rats is due to an increased level of LDL-C taken from the blood circulation. Increased level of TGs is the prime risk factor of MI that is associated with cardiovascular disturbances. CHAE treatment ameliorated lipids and lipoproteins with a significant increase in HDL-C levels and a decrease in TC, TGs, LDL-C, and VLDL-C levels, which may be due to the hypocholesterolemia and hypolipidemic activities of CHAE [33].

\section{Effect of CHAE on LPO}

Fig. 3 represented the effect of CHAE on serum LPO marker MDA in control and ISO-administered rat groups. Rats administered with ISO showed significant $(\mathrm{p}<0.05)$ increase in the level of MDA in serum when compared to control rats. CHAE (100 and $200 \mathrm{mg} / \mathrm{kg} \mathrm{bw})$ dose decreased the level of MDA significantly $(p<0.05)$ in serum as compared to ISO alone administered rats.

LPO plays a crucial role in the toxicity of heart and liver. LPO is an important pathogenic event in myocardial necrosis and accumulation of lipid hydroperoxides which reflects damage to the cardiac constituents [34]. The free radicals mediate membrane damage that may increase the level of lipid peroxides in ISO-administered MI. The present study revealed a significant increase in the level of MDA in the serum of ISO-administered rats. CHAE pre-treatment to ISO-treated rats minimized MDA content, clearly exhibiting that CHAE inhibited the LPO. The inhibition of LPO may be due to the antioxidative activities of CHAE [35].

\section{Effect of CHAE on CAT}

Fig. 4 shows the effect of CHAE on the activity of CAT in the serum of control and ISO-administered rats. Rats administered with ISO significantly $(\mathrm{p}<0.05)$ decreased the activities of CAT in the heart as compared to normal control group. However, treatment with CHAE (100 and $200 \mathrm{mg} / \mathrm{kg}$ ) significantly prevented the reduction in the activities of antioxidant CAT as compared to ISO alone administered rats.

CAT is a common enzyme, found in nearly all living organisms. It catalyzes hydrogen peroxide into water and oxygen and protects organisms from free radicals. CAT has one of the highest turnover numbers of all enzymes; one CAT molecule can convert millions of hydrogen peroxide molecules to water and oxygen each second. CHAE pre-treatment to ISO-treated rats increases the CAT level in serum, clearly exhibiting that CHAE enhanced the CAT activity.

\section{Effect of CHAE on PON enzyme}

Fig. 5 depicts the effect of CHAE on the activity of serum PON in control and experimental rats. Significant $(\mathrm{p}<0.05)$ decrease in the levels of

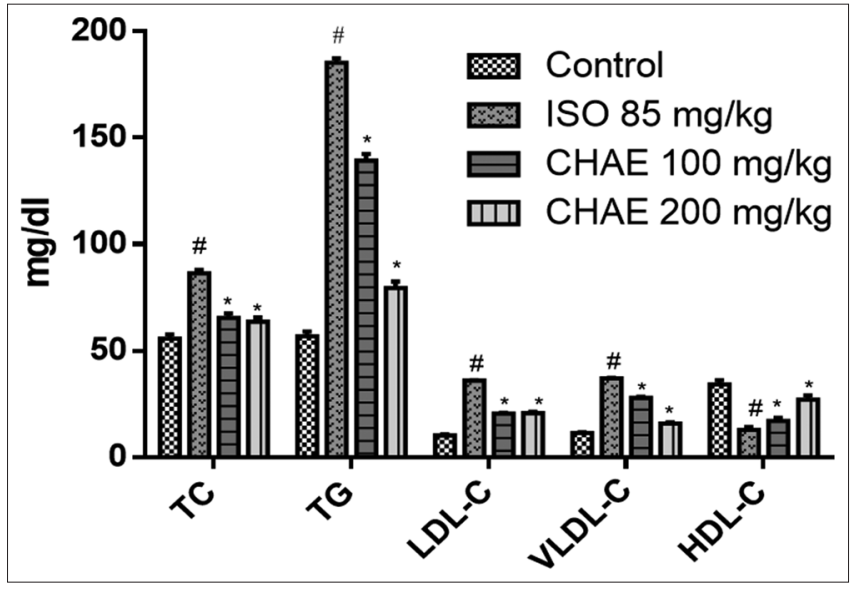

Fig. 2: Effect of CHAE on lipids and lipoproteins in the serum of untreated and isoproterenol-administered rats. The bars represent mean \pm SEM; $\mathbf{n = 6 ;}$; $\mathbf{p}<0.05$ versus control. ${ }^{*} \mathbf{p}<0.05$ versus ISO one-way ANOVA followed by Tukey's multiple comparison tests

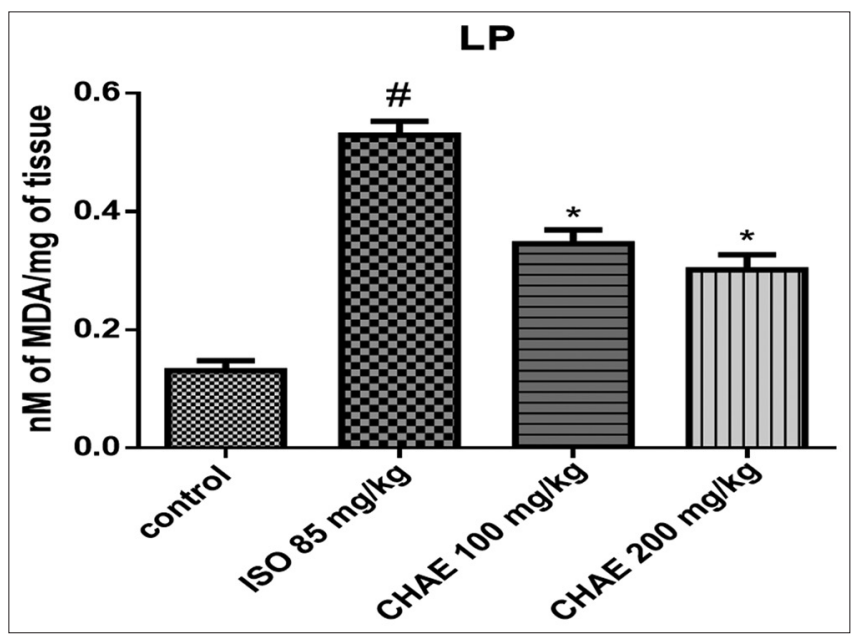

Fig. 3: Effect of CHAE on lipid peroxidation in the serum of untreated and isoproterenol-administered rats. The bars represent mean \pm SEM; $n=6$; ${ }^{*} \mathbf{p}<0.05$ versus control. ${ }^{*} \mathbf{p}<\mathbf{0 . 0 5}$ versus ISO one-

way ANOVA followed by Tukey's multiple comparison tests

serum PON observed in rats administered with ISO as compared to control rats. CHAE (100 and $200 \mathrm{mg} / \mathrm{kg} \mathrm{bw}$ ) pre-treatment for a period of 20 days increased the activity of serum PON significantly $(\mathrm{p}<0.05)$ when compared to ISO alone administered rats.

CHAE treatment has been enhanced PON activity in ISO-treated groups. CHAE may directly elevate serum PON activity because both in vitro and in vivo introduction of antioxidant molecules were shown to preserve PON activity. CHAE may also favorable to PON by its antihypercholesterolemia and antioxidant activities. 


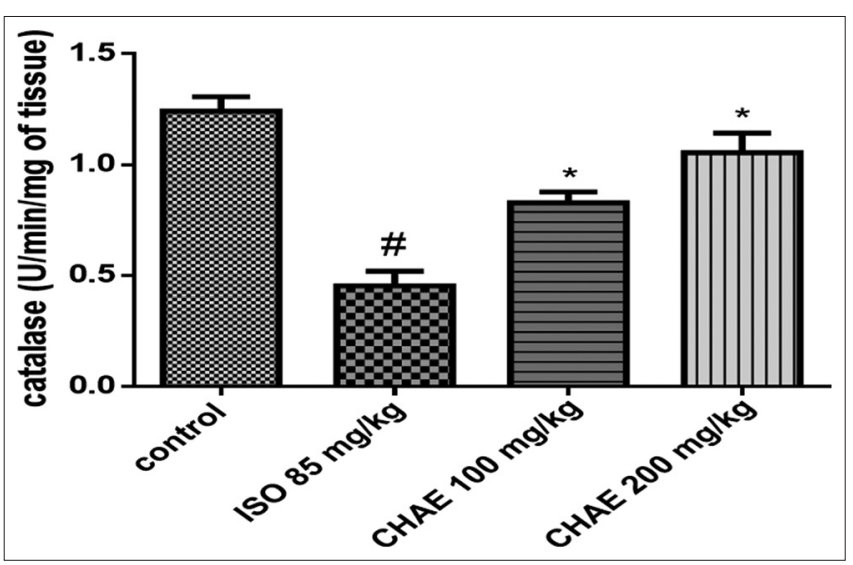

Figure 4: Effect of CHAE on CAT level in the serum of untreated and isoproterenol-administered rats. The bars represent mean \pm SEM; $n=6$; $" \mathbf{p}<0.05$ versus control. ${ }^{*} \mathbf{p}<0.05$ versus ISO oneway ANOVA followed by Tukey's multiple comparison tests

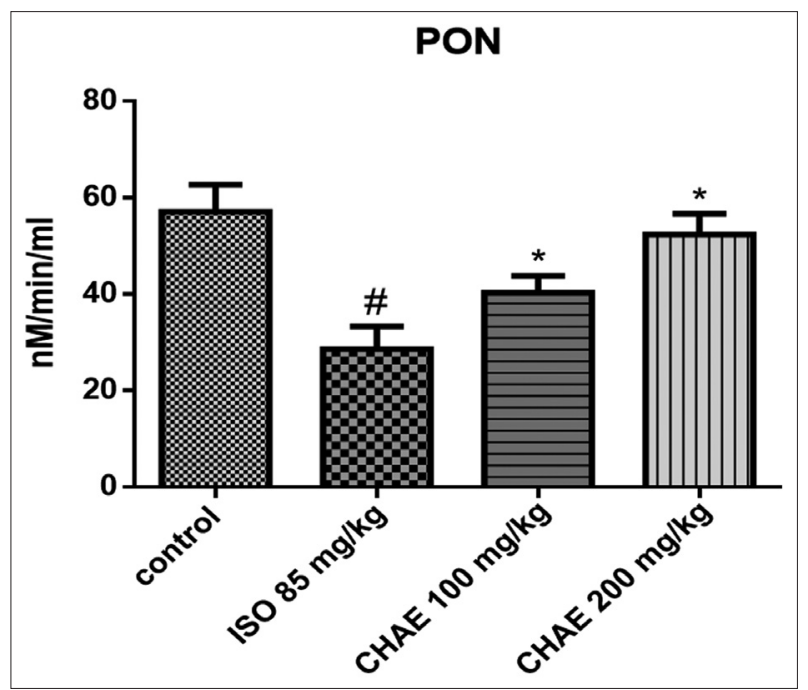

Fig. 5: Effect of CHAE on paraoxonase in the serum of untreated and isoproterenol-administered rats. The bars represent mean \pm SEM; $n=6$; ${ }^{\#}<<0.05$ versus control. ${ }^{*} \mathrm{p}<0.05$ versus ISO oneway ANOVA followed by Tukey's multiple comparison tests

\section{CONCLUSION}

The conclusion of our study is pre-treatment with CHAE exhibits ameliorative effects in ISO injected myocardial infraction rats by modulating lipids, lipoproteins, and antioxidants enzymes such as LPO, CAT, and PON at the dose of $100 \mathrm{mg} / \mathrm{kg}$ and $200 \mathrm{mg} / \mathrm{kg}$ bw. The possible mechanism of CHAE cardioprotection is due to its antihypercholesterolemic, antihyperlipidemic, and antioxidant actions.

\section{ACKNOWLEDGMENTS}

The authors are grateful to the Department of Pharmacology, JSS College of Pharmacy, Ooty, Tamil Nadu, India, for providing the facilities to carry out the present work.

\section{AUTHORS' CONTRIBUTION}

VR designed an entire study project, contributed to experiment finalization and implementation, manuscript editing, and finalization. GA designed and performed experiments.

\section{CONFLICTS OF INTEREST}

The authors declare that they have no conflicts of interest.

\section{REFERENCES}

1. Whellan DJ. Heart failure disease management: Implementation and outcomes. Cardiol Rev 2005;13:231-9.

2. Aronow WS. Epidemiology, pathophysiology, prognosis, and treatment of systolic and diastolic heart failure. Cardiol Rev 2006;14:108-24.

3. Ravichandran V, Hanumantharayappa B, Papasani VM. Evaluation of cardioprotective activity of galangin against doxorubicin induced cardiomyopathy. Int J Pharm Pharm Sci 2014;6:86-90.

4. Goldstein JL, Brown MS. Progress in understanding the LDL receptor and HMG-coA reductase, two membrane proteins that regulate the plasma cholesterol. J Lipid Res 1984;25:1450-61.

5. Abdel-Reheim ES. Cardioprotective efficacy of taurine on lipidmetabolism of isoproterenol-induced myocardial infarction. Int J Pharm Pharm Sci 2016;8:135-41.

6. Singal PK, Kapur N, Dhillon KS, Beamish RE, Dhalla NS. Role of free radicals in catecholamine-induced cardiomyopathy. Can J Physiol Pharmacol 1982;60:1390-7.

7. Naghavi M, Libby P, Falk E, Casscells SW, Litovsky S, Rumberger J, etal. From vulnerable plaque to vulnerable patient: A call for new definitions and risk assessment strategies: Part I. Circulation 2003;108:1664-72.

8. Grieve M, Leyel CF. The medicinal, culinary, cosmetic and economic properties, cultivation and folklore of herbs, grasses, fungi, shrubs and trees with all their modern scientific uses. In: A Modern Herbal. Chatham, Kent: Tiger books International, Mackays of Chatham, PLC; 1994. p. 961-2.

9. Duke JA, Bogenschutz-Godwin MJ, Du Celliar J, Duke PA. Plantago ovata F. In: Hand Book of Medicinal Herbs. $2^{\text {nd }}$ ed. Boca Raton: CRC Press; 2002. p. 174-5.

10. Singh O, Khanam Z, Misra N, Srivastava MK. Chamomile (Matricaria chamomilla L.): An overview. Pharmacogn Rev 2011;5:82-95.

11. de la Motte S, Böse-O'Reilly S, Heinisch M, Harrison F. Doubleblind comparison of an apple pectin-chamomile extract preparation with placebo in children with diarrhea. Arzneimittelforschung 1997;47:1247-9.

12. Baquar SR. Matricaria chamomilla L. In: Medicinal and Poisonous Plants of Pakistan. Karachi, Pakistan: Printas Karachi; 1989. p. 278.

13. Issac O. Recent Progress in Chamomile Research-Medicines of Plant Origin in Modern Therapy. $1^{\text {st }}$ ed. Czecho-Slovakia: Prague Press; 1989.

14. Das M, Mallavarapu GR, Kumar S. Chamomile (Chamomilla recutita): Economic botany, biology, chemistry, domestication and cultivation. J Med Aromat Plant Sci 1998;20:1074-109.

15. Kumar S, Das M, Singh A, Ram G, Mallavarapu GR, Ramesh S. Composition of the essential oils of the flowers, shoots and roots of two cultivars of Chamomilla recutita. J Med Aromat Plant Sci 2001;23: 617-23.

16. Petrul'ová-Poracká V, Repčák M, Vilková M, Imrich J. Coumarins of Matricaria chamomilla L.: Aglycones and glycosides. Food Chem 2013; 141:54-9.

17. Mazokopakis EE, Vrentzos GE, Papadakis JA, Babalis DE, Ganotakis ES. Wild chamomile (Matricaria recutita L.) mouthwashes in methotrexate-induced oral mucositis. Phytomedicine 2005;12:25-7.

18. Maschi O, Cero ED, Galli GV, Caruso D, Bosisio E, Dell' Agli M. Inhibition of human cAMP-phosphodiesterase as a mechanism of the spasmolytic effect of Matricaria recutita L. J Agric Food Chem 2008;56:5015-20.

19. Achterrath-Tuckermann U, Kunde R, Flaskamp E, Isaac O, Thiemer K. Pharmacological investigations with compounds of chamomile. V. Investigations on the spasmolytic effect of compounds of chamomile and kamillosan on the isolated guinea pig ileum. Planta Med 1980;39:38-50

20. Shikov AN, Pozharitskaya ON, Makarov VG, Kvetnaya AS, Antibacterial activity of Chamomilla recutita oil extract against helicobacter pylori. Phytother Res 2008;22:252-3.

21. Kato A, Minoshima Y, Yamamoto J, Adachi I, Watson AA, Nash RJ, et al. Protective effects of dietary chamomile tea on diabetic complications. J Agric Food Chem 2008;56:8206-11.

22. Cemek M, Kağa S, Simșek N, Büyükokuroğlu ME, Konuk M. Antihyperglycemic and antioxidative potential of Matricaria chamomilla L. In streptozotocin-induced diabetic rats. J Nat Med 2008;62:284-93.

23. Kuo CL, La Du BN. Comparison of purified human and rabbit serum paraoxonases. Drug Metab Dispos 1995;23:935-44.

24. Durrington PN, Mackness B, Mackness MI. Paraoxonase and atherosclerosis. Arterioscler Thromb Vasc Biol 2001;21:473-80.

25. Rozenberg O, Rosenblat M, Coleman R, Shih DM, Aviram M. 
Paraoxonase (PON1) deficiency is associated with increased macrophage oxidative stress: Studies in PON1-knockout mice. Free Radic Biol Med 2003;34:774-84.

26. Shaik AH, Shaik NR, Mohammed AK, Al Omar SY, Mohammad A, Mohaya TA, et al. Terminalia pallida fruit ethanolic extract ameliorates lipids, lipoproteins, lipid metabolism marker enzymes and paraoxonase in isoproterenol-induced myocardial infarcted rats. Saudi J Biol Sci 2018;25:431-6

27. Williamson EM, Okpako DT, Evans FJ. Pharmacological Methods in Phytotherapy Research. Chichester: John Wiley and Sons; 1998. p. $15-23$.

28. Khalil MI, Ahmmed I, Ahmed R, Tanvir EM, Afroz R, Paul S, et al. Amelioration of isoproterenol-induced oxidative damage in rat myocardium by Withania somnifera leaf extract. Biomed Res Int 2015; 2015:624159.

29. Allain CC, Poon LS, Chan CS, Richmond W, Fu PC. Enzymatic determination of total serum cholesterol. Clin Chem 1974;20:470-5.

30. Richmond W. Preparation and properties of a cholesterol oxidase from Nocardia sp. And its application to the enzymatic assay of total cholesterol in serum. Clin Chem 1973;19:1350-6.

31. Ohkawa H, Ohishi N, Yagi K. Assay for lipid peroxides in animal tissues by thiobarbituric acid reaction. Anal Biochem 1979;95:351-8

32. Gan A, Smolen HW, Eckerson BN, La Du. Purification of human serum paraoxonase/arylesterase. Evidence for one esterase catalyzing both activities. Am Soc Pharmacol Exp Ther 1991;19:100-6.

33. Anandan R, Mathew S, Sankar TV, Viswanathan Nair PG. Protective effect of n-3 polyunsaturated fatty acids concentrate on isoproterenolinduced myocardial infarction in rats. Prostaglandins Leukot Essent Fatty Acids 2007;76:153-8

34. Gutteridge JM. Free-radical damage to lipids, amino acids, carbohydrates and nucleic acids determined by thiobarbituric acid reactivity. Int J Biochem 1982;14:649-53.

35. Jagadeesh GS, Nagoor Meeran MF, Selvaraj P. Protective effects of 7-hydroxycoumarin on dyslipidemia and cardiac hypertrophy in isoproterenol-induced myocardial infarction in rats. J Biochem Mol Toxicol 2016;30:120-7. 